\title{
Calorimetry, densitometry and ultrasonics: recent contributions to the thermodynamics of fluids *
}

\author{
Jean-Pierre E. Grolier ${ }^{1}$ and Emmerich Wilhelm ${ }^{2}$ \\ 1 Laboratoire de Thermodynamique et Cinétique Chimique, \\ Université Blaise Pascal, F - 63177 Aubière, France \\ 2 Institut für Physikalische Chemie, Universität Wien, \\ Währingerstraße 42, A - 1090 Wien, Austria
}

\begin{abstract}
This article reviews recent advances in the thermodynamics of fluid nonelectrolytes, pure and mixed. The focus is on high-precision experimental techniques and the following topics are included : vapor-liquid equilibrium studies on dilute solutions, calorimetric techniques for measuring heats of mixing and/or solution as well as heat capacities, densitometry at elevated temperatures and pressures, and speed of sound measurements. Some of the problems encountered in data reduction and data correlation will also be indicated.
\end{abstract}

\section{INTRODUCTION}

The assortment of modern intrumentation accessible to today's experimentalists permits the systematic study of thermodynamic properties of fluids and phase equilibria with ever increasing precision and speed over wide temperature and pressure ranges. An exhaustive description of the present status of research in these areas within the constraints imposed by a conference presentation is clearly impossible, and we have limited our survey to a few topics primarily reflecting our own research interests and limitations of expertise. This approach follows the pattern of our recent reviews (1-11), i.e. critical essays rather than exhaustive presentations of the current literature. To summarize, we will focus on dilute nonelectrolyte solutions (vapor-liquid equilibria, enthalpies of solution etc.), excess enthalpies, excess heat capacities and excess volumes of binary liquid mixtures, and the determination of caloric and PVT properties of liquids, incorporating speed-of-sound measurements, over large temperature and pressure ranges. Aqueous solutions of gases and mixtures containing polar subtances are of particular interest. Only a few selected results will be presented and we apologize for the omission of many other equally active topics and important contributions.

\section{DILUTE SOLUTIONS}

Current interest in solution thermodynamics has been mainly stimulated by (a) advances in the theory of liquids in general, (b) advances in experimental techniques providing more accurate data in less time, and (c) the need for thermophysical property data and phase equilibrium data in the applied sciences, for instance the chemical and power industry, geology, the gas, oil and coal industry, pollution control, biomedical technology, etc. Focussing now on binary dilute solutions containing a supercritical solute 2 (a gas) dissolved in liquid solvent 1 , what are the quantities of interest $(1-3,6,7,10) ?$

\footnotetext{
Communicated in two parts as Invited Lectures (part I : J-P. E. G., part II : E. W.) at the 11th International Conference on Chemical Thermodynamics in Como, Italy, 27-31 August 1990.
} 
Isothermal vapor-liquid equilibrium (VLE) measurements in conjunction with the $(\varphi, \gamma)$ approach (unsymmetric convention) yield the Henry fugacity $\mathrm{H}_{2,1}\left(T, P_{s, 1}\right)$ and the corresponding activity coefficient $\gamma_{2}^{\prime}\left(T, P_{s, 1}, x_{2}\right)$ according to the rigorous relations,

$$
H_{2,1}\left(T, P_{s, 1}\right)=\lim _{x_{2} \Rightarrow}\left(\varphi_{2}^{v} y_{2} P / x_{2}\right)
$$

and

$$
\ln _{2}^{\prime}\left(T, P_{s, 1}, x_{2}\right)=\ln \left(\frac{\varphi_{2}^{V} y_{2} P}{x_{2} H_{2,1}\left(T, P_{s, 1}\right.}\right)-\int_{P_{s, 1}}^{P} \frac{v_{2}^{L}}{R T} d P .
$$

Here, $T$ and $P$ denote experimental temperature and pressure, $P_{s, 1}$ is the vapor pressure of the solvent, $x_{2}$ and $y_{2}$ are the mole fractions of the solute in the liquid phase (superscript L) and vapor phase (superscript V), respectively, $\varphi_{2}^{V}$ is the vapor phase fugacity coefficient of the solute, and $v_{2}^{L}$ is its partial molar volume in the liquid phase.

This sequential approach is most frequently used at temperatures well below the critical temperature of the solvent $T_{c, 1}$ and at low to moderate pressures. We note that from the general definition of the component fugacity coefficient, the limiting behavior of the Henry fugacity as $T \Rightarrow T_{c, 1}$ and $P_{s, 1} \Rightarrow P_{c, 1}$ (the critical pressure of the solvent) is given by $(1-3,10)$.

$$
\begin{aligned}
& \lim H_{2,1}\left(T, P_{s, 1}\right)=P_{c, 1} \varphi_{2}^{V_{\infty}}\left(T_{c, 1}, P_{c, 1}\right), \\
& T \Rightarrow T_{c, 1}
\end{aligned}
$$

where $\varphi_{2}^{\mathrm{V} \infty}$ is the fugacity coefficient of the solute at infinite dilution in the vapor phase. Provided that the solute is the more volatile component, Schotte (12) has shown that

$$
\begin{aligned}
& \lim \left[d \operatorname{lnH}_{2,1}\left(T, P_{s, 1}\right) / d T\right]=-\infty \\
& T \Rightarrow T_{c, 1}
\end{aligned}
$$

This behavior has been predicted by Wheeler (13) and Levelt Sengers et al. $(14,15)$.

Both the temperature and pressure dependences of the quantities introduced above are readily calculated $(1-3,6,7,10)$. For instance, with $\tau \equiv 1 / \mathrm{T}$.

$$
\begin{aligned}
& \left(\partial \ln H_{2,1} / \partial \tau\right)_{P}=\Delta H_{2}^{\infty} / R, \\
& \left(\partial^{2} \ln H_{2,1} / \partial \tau^{2}\right)_{P}=-\Delta C_{P, 2}^{\infty} / R \tau^{2},
\end{aligned}
$$

and

$$
\left(\partial \ln \mathrm{H}_{2,1} / \partial \mathrm{P}\right)_{T}=\tau \mathrm{V}_{2}^{\mathrm{L} \infty} / \mathrm{R} \text {. }
$$

Here, $\Delta H_{2}^{\infty}$ is the partial molar enthalpy change on solution, $\Delta C_{P, 2}^{\infty}$ is the partial molar heat capacity change on solution, and $V_{2}^{\mathrm{L} \infty}$ is the partial molar volume of the dissolved gas at infinite dilution.

Equations (5) and (6) are the basis for comparison of calorimetrically determined enthalpy and heat capacity changes on solution (direct methods, (16-25)) with results obtained from van't Hoff analysis of high-precision VLE data of dilute solutions (indirect methods, (26-29)). Figure la shows results for $\mathrm{H}_{2,1}\left(T, P_{s, 1}\right)$ of methane dissolved in water as obtained by Rettich et al. (26), Figure 1b compares the corresponding enthalpies of solution with the direct values reported by Dec and Gill $(19,21,22)$ and Olofsson et al. (17) : excellent agreement is observed throughout. Evidently, for such a comparison the fitting equation representing the temperature dependence of the Henry fugacity has to be judiciously selected. Usually, either a Clarke-Glew type expression (31) or a power 
series in $\tau$, as suggested by Benson and Krause $(32,33)$, is used. Since the $H_{2,1}\left(T, P_{s, 1}\right)$ values at different temperatures refer, of course, to different pressures $P_{s, 1}(T)$, the enthalpy of solution is given by

$$
\Delta \mathrm{H}_{2}^{\infty}\left(T, \mathrm{P}_{\mathrm{s}, 1}\right)=\mathrm{R}\left[\mathrm{d} \ln \mathrm{H}_{2,1}\left(\mathrm{~T}, \mathrm{P}_{\mathrm{s}, 1}\right) / \mathrm{d} \tau\right]-\tau \mathrm{V}_{2}^{\mathrm{L}, \infty}(\mathrm{dP} / \mathrm{s,1} / \mathrm{d} \tau)
$$

with an analogous expression for $\Delta C_{p, 2}^{\infty}(1-3,6,7,10)$. The partial molar heat capacity at infinite dilution diverges, as expected, towards positive infinity $(24,25)$ when the critical point of the solvent is approached from $T<T_{c, 1}$. When $T_{c, 1}$ is approached from higher temperatures, $C_{P, 2}^{\infty}$ tends towards negative infinity.

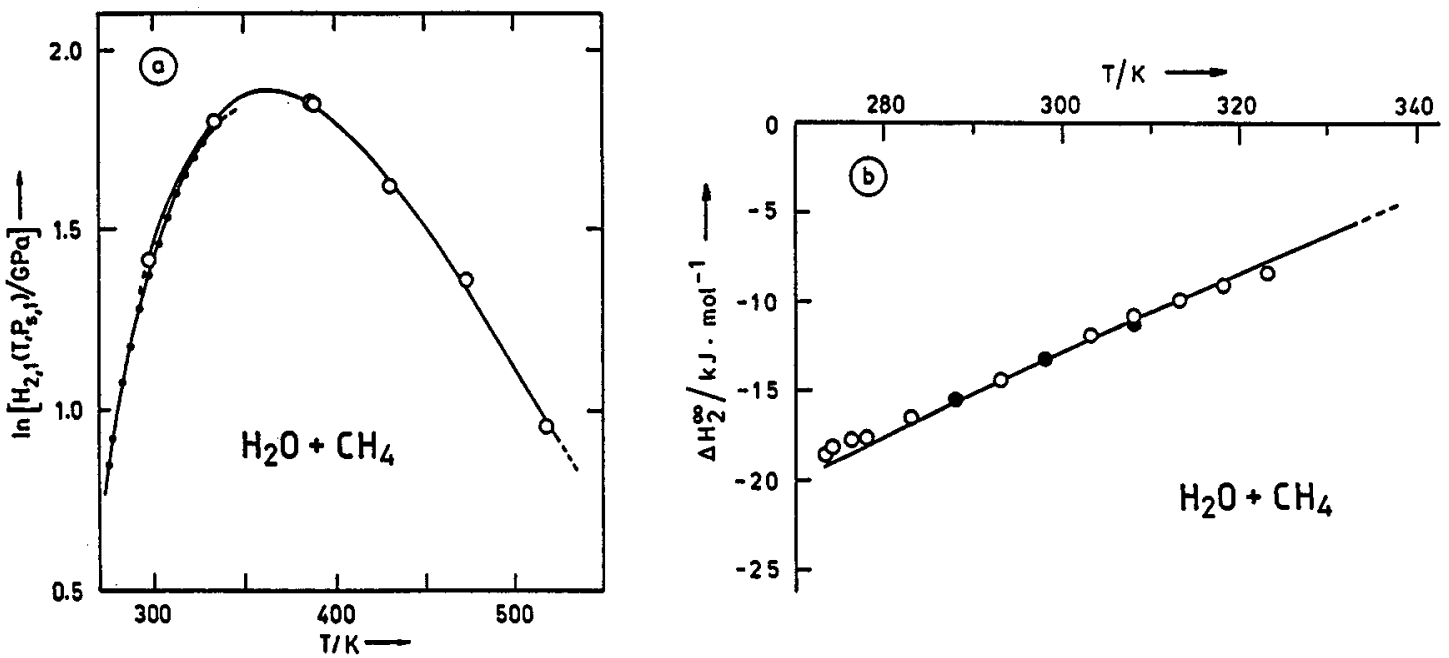

Fig. 1. (a) Plot of $\ln \left[\mathrm{H}_{2,1}\left(\mathrm{~T}, \mathrm{P}_{\mathrm{s}, 1}\right) / \mathrm{GPa}\right]$ against temperature $\mathrm{T}$ for methane dissolved in water : •, Rettich et al. (26) [percentage deviation is ca. $\pm 0.05 \%$ ] ; o, Crovetto et al. (30) [percentage deviation is between 1 and 2\%].

(b) Enthalpy of solution of methane in water from $273.15 \mathrm{~K}$ to $333.15 \mathrm{~K}:-$, Rettich et al. (26); o, Naghibi et al. (22); $\bullet$, Dec and Gill $(19,21)$. At this scale, the results of Olofsson et al. (17) cannot be distinguished from those of Refs. (19, 21, 22). Using Rettich's data (26), the extrapolated temperature where $\Delta \mathrm{H}_{2}^{\infty}=0\left(\mathrm{~T}_{0} \simeq 360 \mathrm{~K}\right)$ is in excellent agreement with the experimental findings, see

Fig. $1 \mathrm{a}$ and eqs. (5) and (8).

The effect of pressure on the Henry fugacity is given by eq. (7). However, simplistic application, in the form of the Krichevsky-Kasarnovsky equation, to extract $V_{2}^{L \infty}$ from high-pressure gas solubility data may yield unreliable results, since Poynting correction and the 'composition effect' embodied in the activity coefficient frequently cancel each other to a significant extent (34, 35). The preferred experimental method for determining $V_{2}^{L \infty}$ (and $V_{2}^{L}$ ) is either dilatometry $(36,37$ ) or densitometry (38-41). The latter has proved particularly valuable for investigating $V_{2}^{\mathrm{L}}$ of dilute solutions in the vicinity of the solvent critical point (41).

\section{MIXTURES}

For liquid mixtures, interest generally focusses on excess molar quantities (symmetric convention), such as $\mathrm{H}^{E}, \mathrm{C}_{\mathrm{P}}^{\mathrm{E}}$ and $\mathrm{V}^{E}$, and their dependence on $\mathrm{T}, \mathrm{P}$ and $\mathrm{x}$. In the past, most experimental calorimetric work was devoted to the determination of excess molar enthalpies $\mathrm{H}^{\mathrm{E}}$, usually at atmospheric pressure. The Picker flow calorimeter for the measurement of "volumetric" heat capacities, i.e. heat capacities per unit volume, $\mathrm{C}_{\mathrm{P}} / \mathrm{V}$, was the major step forward towards creation of a large and reliable data base of excess molar heat capacities $C_{P}^{E}=\left(\partial H^{E} / \partial T\right)_{P, x}$ for liquid mixtures of nonelectrolytes (42-45). The main asset of this type of intrument is its high sensitivity, permitting the accurate determination of the composition dependence of $C_{p}^{E}$ at a given temperature, coupled with easy handling, low substance consumption and speed of an actual experiment. Together with flow calorimeters for measuring $\mathrm{H}^{\mathrm{E}}$ and vibrating-tube densitometers for 

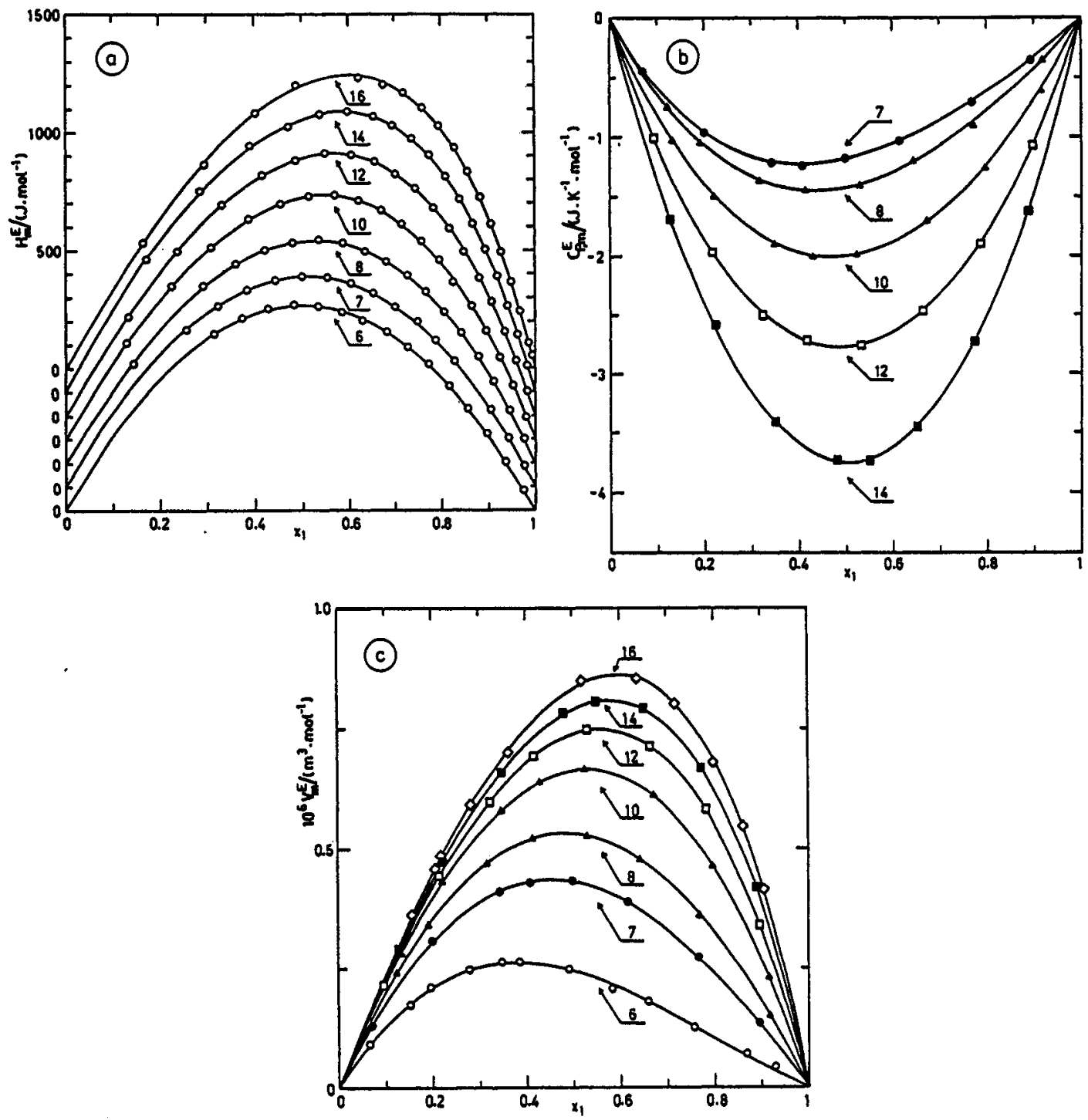

Fig. 2. (a) Excess molar enthalpies of $\left\{x_{1} C_{6} H_{5} F+x_{2} n-C_{1} H_{21+2}\right\}$ at $298.15 \mathrm{~K}$ and $0.1 \mathrm{MPa}$. Circles denote experimental points (52), the number are values of the chain length 1 of the n-alkane.

(b) Excess molar heat capacities of $\left\{\mathrm{x}_{1} \mathrm{C}_{6} \mathrm{H}_{5} \mathrm{~F}+\mathrm{x}_{2} \mathrm{n}-\mathrm{C}_{1} \mathrm{H}_{21+2}\right\}$ at $298.15 \mathrm{~K}$ and $0.1 \mathrm{MPa}$. The experimental results are from Ref. (52), the numbers are values of the chain

(c) Excess molar volumes of $\left\{x_{1} C_{6} H_{5} F+x_{2} n-C_{1} H_{21+2}\right\}$ at $298.15 \mathrm{~K}$ and $0.1 \mathrm{MPa}$. The experimental results are from Ref. (52), the numbers are values of the chain length 1 of the n-alkane.

measuring excess molar volummes $\mathrm{V}^{\mathrm{E}}$, we now have at hand a group of highly versatile instruments allowing the systematic investigation of classes of liquid mixtures within a reasonably short time, see Fig. 2. Some representative articles are listed as Refs. (46-54). A wealth of new information concerning, in particular, the morphology of curves $C_{p}^{E}$ vs. $x$ was thereby obtained and has led to exciting new developments $(9,10,46,48-50,53,55-63)$. Perhaps one of the most prominent results, the $W$-shaped curves $C_{P}^{E}$ vs. $X$ in binary systems of type $(Y+$ an alkane), where $Y$ denotes a strongly polar substance, is represented by our results (58) for pyridine + an n-alkane shown in Fig. 3. 


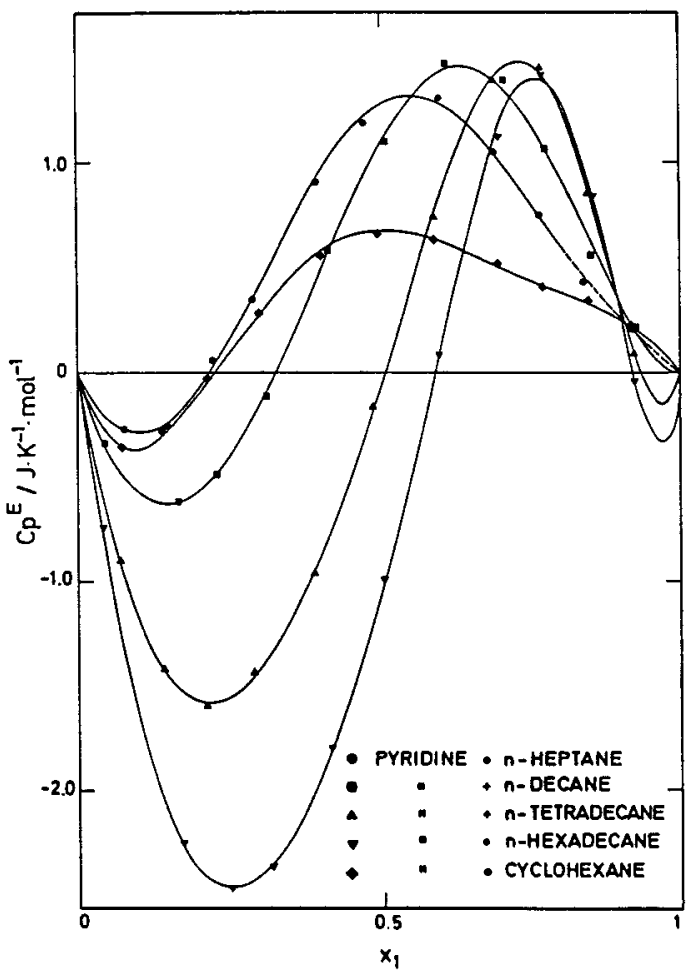

Fig. 3. Excess molar heat capacities of $\left\{x_{1} C_{5} H_{5} N+x_{2} n-C_{1} H_{21+2}\right\}$ and of $\left\{x_{1} C_{5} H_{5} N+x_{2} c-C_{6} H_{12}\right\}$ at $298.15 \mathrm{~K}$ and $0.1 \mathrm{MPa}(58)$.

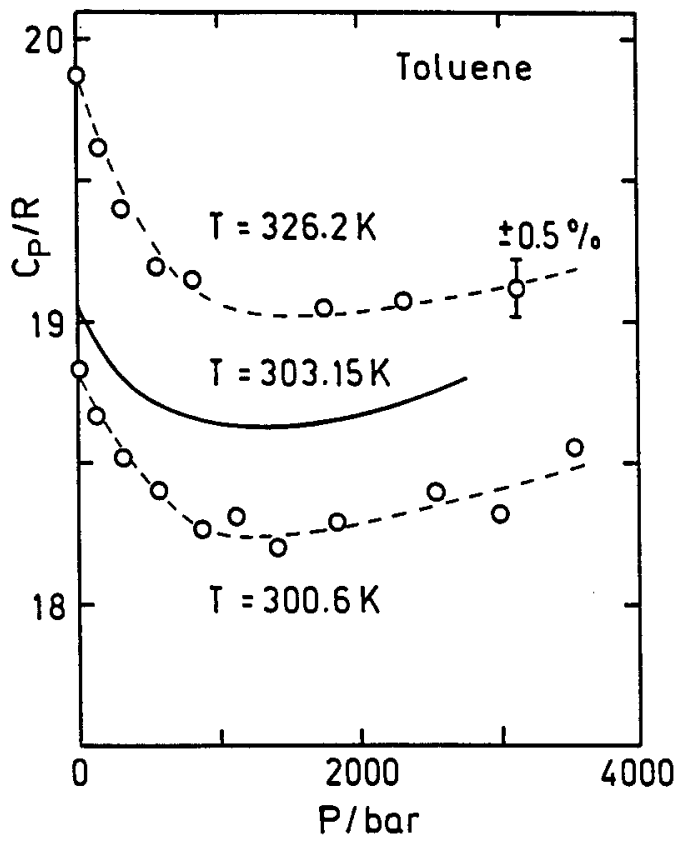

Fig. 4. Pressure dependence of the molar heat capacity $\mathrm{C}_{\mathrm{p}}$ of toluene :- Asenbaum et al. (71) at $303.15 \mathrm{~K}$; --0--, direct experimental results of Shulga et al. (72) at $300.6, \mathrm{~K}$ and $326.2 \mathrm{~K}$, respectively.

\section{THERMOPHYSICAL PROPERTIES OF LIQUIDS AT ELEVATED TEMPERATURES AND/OR PRESSURES}

The data needs of the applied sciences, in particular at elevated temperatures and pressures, have already been indicated. Quantities of interest are, for example, density $\rho$, heat capacity $C_{P}$ and heat capacity $C_{v}$ at constant volume, and various derived quantities, such as isothermal compressibility $\beta_{T}$ and isobaric expansivity $\alpha_{P}$.

For the measurement of $C_{P} / V$ of liquids in the temperature range $273-373 \mathrm{~K}(\mathrm{P} \approx 0.1 \mathrm{MPa})$, we currently use a programmable differential scanning calorimeter (Micro DSC, from Setaram) which is based on the Calvet principle. The sample size is about $1 \mathrm{~cm}^{3}$, the imprecision amounts to about $\pm 0.01 \%(64)$. Combining our results with data on density, expansivity and ultrasonic speed, both $C_{V}$ and $\beta_{T}$ (indirect method, see Ref. (65)) may be obtained from

$$
\begin{aligned}
& C_{P} / C_{V}=\beta_{T} / \beta_{S}=\kappa, \\
& \kappa=1+T M \alpha_{P}^{2} u_{0}^{2} / C_{P},
\end{aligned}
$$

where $u_{0}$ is the speed of ultrasound at low frequency (negligible dispersion) and $\beta_{s}=1 /\left(\rho u_{0}^{2}\right)$ is the isentropic compressibility.

In the range 300-570 $\mathrm{K}$ and for pressures $\mathrm{P} \leq 30 \mathrm{MPa}$ we are using a modified $\mathrm{C} 80$ calorimeter from Setaram. Here the cell volume is about $8 \mathrm{~cm}^{3}$, the imprecision is about $\pm 0.1 \%$. First results on the heat capacity of concentrated salt solutions have already been reported in Refs. $(66,67)$.

An alternative to the direct experimental route to high-pressure volumetric data and $C_{P}(T, P)$ is to measure $u_{0}$ as a function of $P$ and $T$, and to combine these results with data on $\rho$ and $C_{P}$ at ordinary 
pressure $P_{1}=0.1 \mathrm{MPa}$, i.e. one utilizes the integrated form of eq. (9)

$$
\rho(T, P)=\rho\left(T, P_{1}\right)+\int_{P_{1}}^{P} u_{0}^{-2} d P+T M \int_{P_{1}}^{P} \alpha_{P}^{2} C_{P}^{-1} d P,
$$

together with the exact thermodynamic relation

$$
\left(\partial C_{P} / \partial P\right)_{T}=-T V\left[\alpha_{P}^{2}+\left(\partial \alpha_{P} / \partial T\right)_{P}\right]
$$

and a suitable integration algorithm (68-70). The $303.15 \mathrm{~K}$ isotherm of $C_{P}$ vs. $P$ of toluene obtained in this way is shown in Fig. 4 (71), together with two directly determined isotherms at $300.6 \mathrm{~K}$ and $326.2 \mathrm{~K}$, respectively (72). Note the shallow minimum at about $125 \mathrm{MPa}$, which agrees with the negative value of $\left(\partial \alpha_{P} / \partial T\right)_{P}$ observed for toluene at pressure $P \geq 65 \mathrm{MPa}$. (see eq. (11)). Qualitatively similar pressure dependences of $C_{p}$ are now known for several relatively simple liquids.

We conclude this review by presenting an automated pressure-controlled scanning calorimeter (11, 73-79) operating at pressures up to $500 \mathrm{MPa}$ and in the temperature range $300 \mathrm{~K}$ to $570 \mathrm{~K}$. This novel instrument was built in close collaboration with the Institute of Physical Chemistry of the Academy of Sciences in Warsaw; it is shown schematically in Fig. 5. Isobaric expansivity $\alpha_{P}(T, P)$ can be measured in such a calorimeter by either a stepwise method or by continuous (linear) pressure scanning. In the latter case

$$
\alpha_{\mathrm{p}}=-\dot{\mathrm{Q}} /(\mathrm{vT} \dot{\mathrm{P}}),
$$

where $\dot{Q}$ is the thermal power generated or absorbed by the pressure change (under isothermal) conditions), $\dot{P}$ is the rate of pressure change, and $v$ is the volume of substance contained in the calorimetric vessel. The rate of linear pressure variation is typically $20 \mathrm{kPa}^{-1}$, but can be as low as $5 \mathrm{kPa} . \mathrm{s}^{-1}$. Results obtained so far for $\alpha_{\mathrm{p}}$ of $\mathrm{n}$-hexane for pressures up to $350 \mathrm{MPa}$ (11, 78, 79) are in excellent agreement with the literature data (80, 81). This apparatus can also be used to measure the isothermal compressibility.

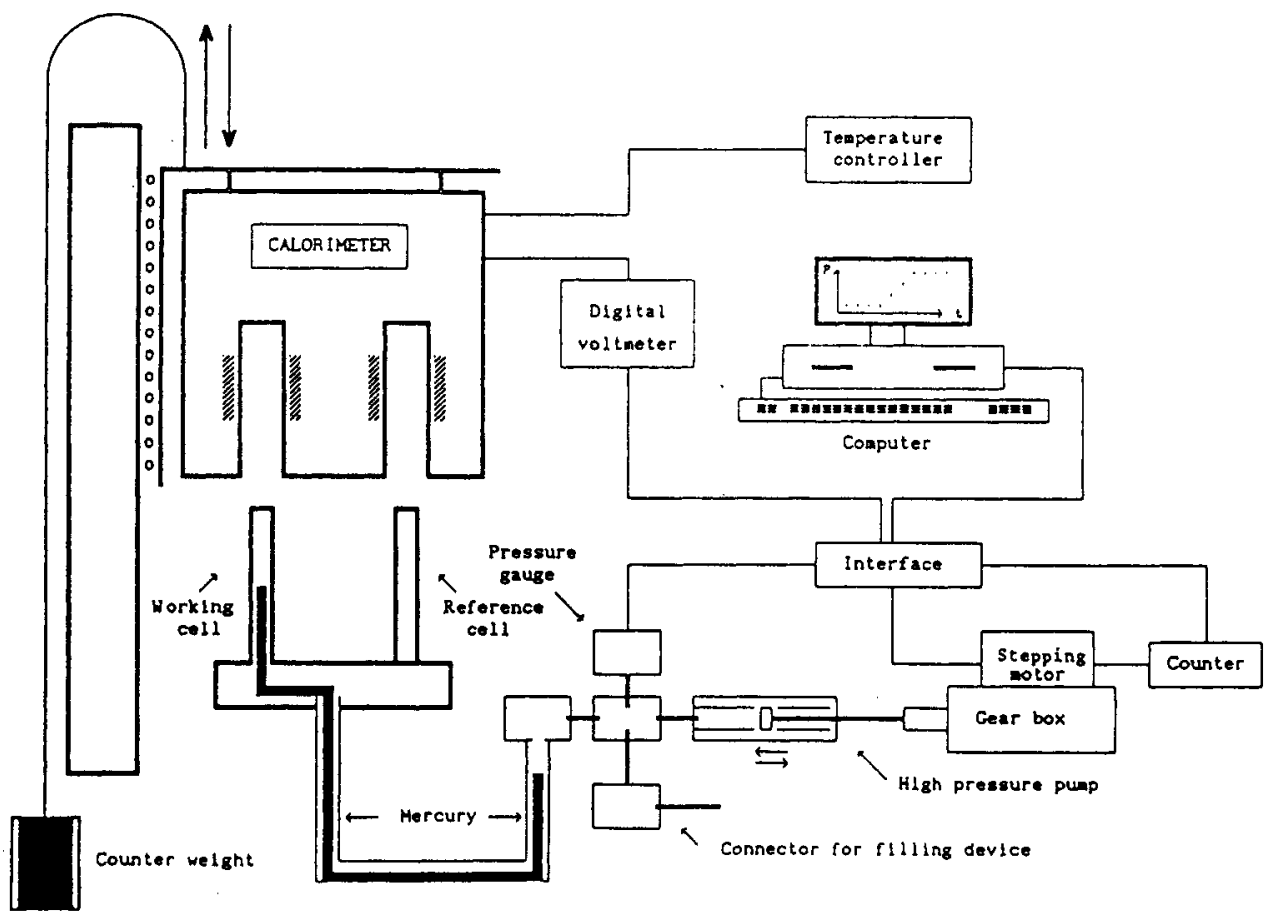

Fig. 5. Schematic diagram of the automated pressure controlled scanning calorimeter. Working and reference cells are kept at a fixed position and are connected to the pressure controlling device. The thermal detector is a C80 calorimeter (from Setaram). It is inverted on a special stand so that it can be moved up and down over the calorimeter cells by means of a counterweight. 


\section{REFERENCES}

1. E. Wilhelm, Pure Appl. Chem., 57, 303 (1985).

2. E. Wilhelm, Precision Methods for the Determination of the Solubility of Gases in Liquids, in : CRC Crit. Rev. Anal. Chem., 16, 128-175 (1985).

3. E. Wilhelm, Fluid Phase Equil., 27, 233 (1986).

4. J-P.E. Grolier, G. Roux-Desgranges and A.H. Roux, Fluid Phase Equil., 30, 157 (1986).

5. E. Wilhelm, Heat Capacities, Isothermal Compressibilities and Related Quantities of Fluids, in : Les capacités calorifiques des systèmes condensés, H. Tachoire, ed., pp. 138-163. Société Française de Chimie (1987).

6. E. Wilhelm, Dilute Aqueous Solutions of Nonelectrolytes : Recent Advances, in : Interactions of Water in Ionic and Nonionic Hydrates, H. Kleeberg, ed., pp. 117-123. Springer, Berlin (1987).

7. E. Wilhelm, Thermochim. Acta, 119, 17 (1987).

8. A.H. Roux, G. Roux-Desgranges, J.R. Quint and J-P.E. Grolier, Measurements of Heat Capacities of Liquids. Pure Liquids, Mixtures, Solutions, in : Experimental Thermodynamics : Measurement and Correlation, S. Malanowski and A. Anderko, eds., pp. 200-218. Inst. Phys. Chem. Pol. Acad. Sci., Warszawa (1988).

9. E. Wilhelm, Calorim. Anal. Therm., 20/21, 413 (1990).

10. E. Wilhelm, Thermochim. Acta, 162, 43 (1990).

11. J-P.E. Grolier, Pure Appl. Chem., 62, 2115 (1990).

12. W. Schotte, AIChE J., 31, 154 (1985).

13. J.C. Wheeler, Ber. Bunsenges. Phys. Chem., 76, 308 (1972).

14. J.M.H. Levelt Sengers, R.F. Chang and G. Morrison, ACS Symp. Ser., 300, 110 (1986).

15. R.F. Chang and J.M.H. Levelt Sengers, J. Phys. Chem., 90, 5921 (1986).

16. S.J. Gill and I. Wadsö, J. Chem. Thermodyn., 14, 905 (1982).

17. G. Olof sson, A.A. Oshodj, E. Qvarnström and I. Wadsö, J. Chem. Thermodyn., 16, 1041 (1984).

18. S.F. Dec and S.J. Gill, Rev. Sci. Instrum., 55, 765 (1984).

19. S.F. Dec and S.J. Gill, J. Solution Chem., 13, 27 (1984).

20. S.F. Dec and S.J. Gill, J. Solution Chem., 14, 417 (1985).

21. S.F. Dec and S.J. Gill, J. Solution Chem., 14, 827 (1985).

22. H. Naghibi, S.F. Dec and S.J. Gill, J. Phys. Chem., 90, 4621 (1986).

23. H. Naghibi, S.F. Dec and S.J. Gill, J. Phys. Chem., 91, 245 (1987).

24. D.R. Biggerstaff, D.E. White and R.H. Wood, J. Phys. Chem., 89, 4378 (1985).

25. D.R. Biggerstaff and R.H. Wood, J. Phys. Chem., 92, 1994 (1988).

26. T.R. Rettich, Y.P. Handa, R. Battino and E. Wilhelm, J. Phys. Chem., 85, 3230 (1981).

27. T.R. Rettich, R. Battino and E. Wilhelm, Ber. Bunsenges. Phys. Chem., 86, 1128 (1982).

28. T.R. Rettich, R. Battino and E.Wilhelm, J. Solution Chem., 13, 335 (1984).

29. T.R. Rettich, E.Wilhelm and R. Battino, presented at the 4th International Symposium on Solubility Phenomena, Troy, New York, USA, July 30 - August 3, 1990.

30. R. Crovetto, R. Fernandez-Prini and M.L. Japas, J. Chem. Phys., 76, 1077 (1982).

31. E.C.W. Clarke and D.N. Glew, Trans. Faraday Soc., 62, 539 (1966).

32. B.B. Benson, and D. Krause, J. Chem. Phys., 64, 689 (1976).

33. B.B. Benson, and D. Krause and M.A. Peterson, J. Solution Chem., 8 , 655 (1979).

34. P.M. Mathias and J.P. O'Connell, Chem. Eng. Sci., 36, 1123 (1981).

35. E.A. Campanella, P.M. Mathias and J.P. O'Connell, AIChE J., 33, 2057 (1987).

36. J. Horiuti, Sci. Pap. Inst. Phys. Chem. Res. (Tokyo), 17, 125 (1931).

37. Y.P. Handa, P. J. D'Arcy and G.C. Benson, Fluid Phase Equil., 8, 181 (1982).

38. J.C. Moore, R. Battino, T.R. Rettich, Y.P. Handa and E. Wilhelm, J. Chem. Eng. Data, 27, 22 (1982).

39. N. Bignell, J. Phys. E : Sci. Instrum., 15, 378, (1982).

40. N. Bignell, (a) J. Phys. Chem., 88, 5409 (1984) ; (b) ibid., 91, 1687 (1987).

41. D.R. Biggerstaff and R.H. Wood, J. Phys. Chem., 92, 1988 (1988).

42. J-L. Fortier, G.C. Benson and P. Picker, J. Chem. Thermodyn., 8, 289 (1976). 
43. J-L. Fortier and G.C. Benson, J. Chem. Thermodyn., 8, 411 (1976).

44. E. Wilhelm, J-P.E. Grolier and M.H. Karbalai Ghassemi, Ber. Bunsenges. Phys. Chem., 81, 925 (1977).

45. J-P.E. Grolier, E. Wilhelm and M.H. Hamedi, Ber. Bunsenges. Phys. Chem., 82, 1282 (1978).

46. E. Wilhelm, Ber. Bunsenges. Phys. Chem., 81, 1150 (1977).

47. E. Wilhelm, A. Inglese, J-P.E. Grolier and H.V. Kehiaian, Monatsh. Chem., 109, 235 \& 435 (1978).

48. E. Wilhelm, A. Inglese, J-P.E. Grolier and H.V. Kehiaian, Ber. Bunsenges. Phys. Chem., 82, 384 (1978).

49. A. Inglese, E. Wilhelm, J-P.E. Grolier and H.V. Kehiaian, J. Chem. Thermodyn., 12, $217 \& 1047$ (1980).

50. J-P.E. Grolier, A. Inglese, A.H. Roux and E. Wilhelm, Ber. Bunsenges. Phys. Chem., 88, 768 (1981).

51. A. Inglese, J-P.E. Grolier and E. Wilhelm, J. Chem. Eng. Data, 28, 124 (1983).

52. A.H. Roux, J-P.E. Grolier, A. Inglese and E. Wilhelm, Ber. Bunsenges. Phys. Chem., 88, 986 (1984).

53. E. Wilhelm, A. Inglese, A.H. Roux and J-P.E. Grolier, Fluid Phase Equil., 34, 49 (1987).

54. E. Wilhelm, A. Lainez and J-P.E. Grolier, Fluid Phase Equil., 49, 239 (1989).

55. J-P.E. Grolier, A. Inglese and E. Wilhelm, J. Chem. Thermodyn., 16, 67 (1984).Experimental results were first reported at the 37th Calorimetry Conference, Snowbird,Utah, USA, 20-23 July 1982, Paper $N^{\circ} 54$.

56. A. Inglese, J-P.E. Grolier and E. Wilhelm, Fluid Phase Equil., 15, 287 (1984).

57. A. Lainez, E. Wilhelm, G. Roux-Desgranges and J-P.E. Grolier, J. Chem. Thermodyn., 17, 1153 (1985).

58. E. Wilhelm, A.H. Roux, G. Roux-Desgranges, M. Rodrigo, A. Lainez and J-P.E. Grolier, Calorim. Anal. Therm., 17, 12 (1986).

59. M-E. Saint-Victor and D. Patterson, Fluid Phase Equil., 35, 237 (1987).

60. H. Kalali, F. Kohler and P. Svejda, Monatsh. Chem., 118, 1 (1987).

61. C Casanova, E. Wilhelm, J-P.E. Grolier and H.V. Kehiaian, J. Chem. Thermodyn., 13, 241 (1981).

62. A. Lainez, M.M. Rodigo, E. Wilhelm and J-P.E. Grolier, J. Chem. Eng. Data, 34, 332 (1989).

63. E. Wilhelm, E. Jimenez, G. Roux-Desgranges and J-P.E. Grolier, J. Solution Chem., 20,17 (1991).

64. A.H. Roux, J-P.E. Grolier and E. Wilhelm, 12th European Conference on Thermophysical Properties, Wien, Austria, 24-28 Septembre 1990.

65. A. Asenbaum and E. Wilhelm, Adv. Molec. Relax. Interact. Processes, 22, 187 (1982).

66. J-Y. Coxam, J.R. Quint and J-P.E. Grolier, J. Chem. Thermodyn., 23, in press (1991).

67. J-Y. Coxam, J.R. Quint and J-P.E. Grolier, 12th European Conference on Thermophysical Properties, Wien, Austria, 24-28 September 1990.

68. M.J.P. Muringer, N.J. Trappeniers and S.N. Biswas, Phys. Chem. Liq., 14, 273 (1985).

69. T.F. Sun, P.J. Kortbeek, N.J. Trappeniers and S. N. Biswas, Phys. Chem. Liq., 16, 163 (1987).

70. T.F. Sun, C.A. Ten Seldam, P.J. Kortbeek, N.J. Trappeniers and S.N. Biswas, Phys. Chem. Liq., 18,107 (1988).

71. A. Asenbaum, E. Wilhelm and P. Soufi-Siavoch, Acustica, 68, 131 (1989).

72. V.M. Shulga, F.G. Eldarov, Yu.A. Atanov and A.A. Kuyumchev, Int. J. Thermophys., 7, 1147 (1986).

73. L. Ter Minassian and P. Pruzan, J. Chem. Thermodyn., 9, 375 (1977).

74. L. Ter Minassian and F. Milliou, J. Phys. E : Sci. Instrum., 16, 450 (1983).

75. S.L. Randzio, J. Phys. E. : Sci. Instrum., 16, 691 (1983).

76. S.L. Randzio, J. Phys. E. : Sci. Instrum., 17, 1058 (1984).

77. S.L. Randzio, Thermochim. Acta, 89, 215 (1985).

78. S.L. Randzio, D.J. Eatough, E.A. Lewis and L.D. Hansen, J. Chem. Thermodyn., 20, 937 (1988).

79. S.L. Randzio, J-P.E. Grolier and J.R. Quint, Calorim. Anal. Therm., 20/21, 315 (1990).

80. E. Kuss and M. Taslimi, Chem. Ing. Techn., 42, 1073 (1990).

81. P. Pruzan, J. Phys. Lett. (Paris), 45273 (1970). 